\title{
A importância interdisciplinar em mostra de trabalhos na Escola Municipal de Ensino Fundamental Santa Rosa, Formigueiro, Rio Grande do Sul
}

The importance of interdisciplinary work shows in Municipal Elementary School Santa Rosa, Formigueiro, Rio Grande do Sul

\author{
Luiz Liberato Costa Corrêa'; Jusarra Pires de Fraga²; Saionara Moreira²; Daniela Peixoto²; \\ Daniele Grigoletto
}

\footnotetext{
' PPG em Biologia, Universidade do Vale do Rio dos Sinos, São Leopoldo, RS, Brasil.

${ }^{2}$ Escola Municipal de Ensino Fundamental Santa Rosa, Formigueiro - RS, Brasil.
}

\section{Resumo}

O presente trabalho tem por finalidade divulgar dados relevantes sobre a primeira mostra de trabalhos interdisciplinar envolvendo em parceria professores de artes, ciências, letras e pedagogia em conjunto com alunos na Escola Municipal de Ensino Fundamental Santa Rosa, município de Formigueiro, Rio Grande do Sul. Contribuindo assim para o desenvolvimento e conhecimento escolar, aliado a pesquisa, cultura e interação entre escola, alunos e comunidade local.

Palavras-chave: Atividades escolares, Educação, Interdisciplinaridade.

\begin{abstract}
This paper aims to disseminate relevant information on the first show of interdisciplinary work involving teachers in partnership arts, science, literature and pedagogy together with students in Municipal Elementary School Santa Rosa in municipality of Formigueiro, Rio Grande do Sul. Thus contributing to the development and school knowledge, combined with scientific research, culture and interaction between school, students and local community.
\end{abstract}

Keywords: School activities, Education, Interdisciplinary. 


\section{INTRODUÇÃO}

A interdisciplinaridade entre as disciplinas na escola torna-se uma aliada importante buscando uma melhor compressão da parceria em estudos e pesquisas, onde as áreas de artes, ciências, letras e pedagogia podem realizar parcerias escolares em mostras de trabalhos, complementando o ensino e assim desenvolvendo a pesquisa e mudanças intelectuais entre os alunos em termos científicos, culturais e sociais.

A sensibilização, a inteligência e a criatividade precisam ser compreendidas e desenvolvidas na escola (MEZZARI, FROTTA, MARTINS, 2011), sendo que há tempos um acelerado desenvolvimento exige que uma nova maneira de ensinar e aprender seja incluída no cotidiano escolar (MAINARDI, MULLER, PEREIRA, 2014). Nesse contexto, a educação necessita buscar alternativas de ensino que motivem os alunos e despertem seu interesse pelo aprender, desenvolvendo assim a habilidade de autonomia. Frente a isso a escola em geral tem um papel significativo no desenvolvimento de conhecimento científico mediante ao aluno e comunidade (LENZ \& HERBER, 2013).

O processo de ensino na Educação Escolar precisa ultrapassar a caracterização em transmissão de conteúdos até alcançar a construção de saberes (NEUENFELDT \& RODRIGUES, 2011) e o professor necessita integrar-se, provocar a curiosidade e criatividade do aluno buscando novos caminhos de aprendizagem (MAINARDI, MULLER, PEREIRA, 2014), possibilitando ao aluno sua manifestação por meio de atitudes, reflexão, análise e pesquisa, sendo essenciais na sua formação escolar (MEZZARI, FROTTA, MARTINS, 2011). Muitas escolas ainda evitam os trabalhos com projetos, as feiras, as mostras por envolverem tempo, continuando ainda de modo tradicional, esquecendo que para ensinar devem ser observados alguns fatores que propiciem um aprendizado significativo, como as condições que contribuam e que motivem o prazer de ensinar e de aprender (MEZZARI, FROTTA, MARTINS, 2011). No entanto, se formos observar na grande maioria dos eventos em mostras ou feiras de trabalhos em escolas de ensino fundamental geralmente é direcionada a disciplina de ciências, no entanto, tornam-se importantes mostras de trabalhos em parceria entre ciências e outras disciplinas proporcionando novas alternativas de ensino aliadas a meios científicos e culturais incentivando a pesquisa e o trabalho em equipe num contexto geral por parte de professores, escola, alunos e comunidade.

Nesse contexto, o presente trabalho tem por finalidade divulgar dados gerais da $1^{\circ}$ mostra de trabalhos interdisciplinar envolvendo em parceria professores de arte, ciências, letras e pedagogia, em conjunto com alunos do ensino fundamental na Escola Municipal de Ensino Fundamental Santa Rosa no município de Formigueiro, RS.

\section{MATERIAL E MÉTODOS}

Foi realizado em 02 de Julho de 2013 a $1^{\text {a }}$ Mostra de trabalhos na Escola Municipal de Ensino Fundamental Santa Rosa, Formigueiro, Rio Grande do Sul, de forma interdisciplinar entre professores de arte, ciências, letras e pedagogia do ensino fundamental.

Trabalhos relacionados às disciplinas abordados na teoria em sala de aula foram apresentados na prática a comunidade local, de acordo com temas pré-estabelecidos em forma de baners, maquete, desenho (pinturas figurativas), degustações de chás e sucos, e processos químicos relacionados às misturas em água, onde alguns alunos de $6^{\circ}$ a $9^{\circ}$ anos participaram juntamente com os professores e direção geral da escola na organização da mostra de trabalho.

Alunos de anos iniciais também participaram apresentando trabalhos em forma de cartaz em temas relacionados ao meio ambiente e sua importância.

De acordo com Santos (2002) o estudo caracterizou-se como uma pesquisa-ação, onde os participantes envolvem-se de forma geral em contribuições e pesquisa de forma direta e indireta, abordando e apresentado um estudo bibliográfico, de campo, experimental, interagindo e apresentando resultados. Proporcionando assim momentos de conhecimento e aprendizado. 


\section{RESULTADOS E CONSIDERAÇÕES FINAIS}

Através da parceria entre professores e escola foi realizado um convite a comunidade em geral e meio escolar do município de Formigueiro para conhecer o trabalho interdisciplinar entres as disciplinas, onde os alunos sob orientação dos professores apresentaram os trabalhos em informações de forma figurativa e oral, proporcionando assim momentos de conhecimentos e troca de experiências, quanto incentivando as práticas escolares.

$\mathrm{Na}$ área de ciências os trabalhos apresentados em forma de baners relatavam pesquisas preventivas e educativas sobre serpentes peçonhentas, mitos e verdades sobre anfíbios, a importância das vitaminas para o corpo humano em geral, gravidez na adolescência, doenças sexualmente transmissíveis e célula animal. Uma breve sobre a importância da medicina natural com degustação de chás e os efeitos em processos químicos relacionados à água. Exposição de espécimes taxidermizados também foi apresentada, visando o conhecimento da fauna local aliado a educação ambiental. Na área de Artes trabalhos realizados pelos alunos em desenhos e pinturas foram expostos. Na parte pedagógica em anos iniciais alguns alunos em forma de cartazes realizaram desenhos e colagens sobre a biodiversidade local e caracterizaram a importância do ciclo das águas (Figura 1).

Conforme relatos aleatórios dos participantes e visitantes na mostra de trabalhos, a iniciativa do estudo foi muito importante onde proporcionou momentos de descontração e conhecimento onde os alunos passaram de ser espectadores e se tornaram apresentadores. Para Mezzari, Frotta, Martins (2011) é fundamental que a escola propicie momentos de diálogo entre as disciplinas, contribuindo para a busca da indissociabilidade em atividades de ensino e pesquisa (STÜLP et al., 2013).

Através das práticas interdisciplinares na escola entre professores conjuntamente com os alunos, é possível romper os limites estritamente disciplinares contribuindo assim com o ensino-aprendizagem, implementando unidades didáticas e novas possibilidades de estudo (NEUENFELDT \& RODRIGUES, 2011). Nesse contexto a participação da comunidade interna e externa e por meio de atividades diversificadas são importantes visando e proporcionando um aprendizado significativo (MEZZARI, FROTTA, MARTINS, 2011).

Com base nos resultados através da $1^{\circ}$ Mostra de trabalhos na Escola Santa Rosa, fica clara a importância da interdisciplinaridade entre as disciplinas em parceria com professores, alunos e escola, onde conhecimentos, sensibilidade e pesquisa proporcionaram momentos de interação, contribuindo assim para o ensino básico fundamental. Devemos destacar a importância de projetos e mostras de trabalhos na escola, no entanto, é necessária a publicação desses estudos em periódicos especializados apresentando suas atividades didáticas e resultados.

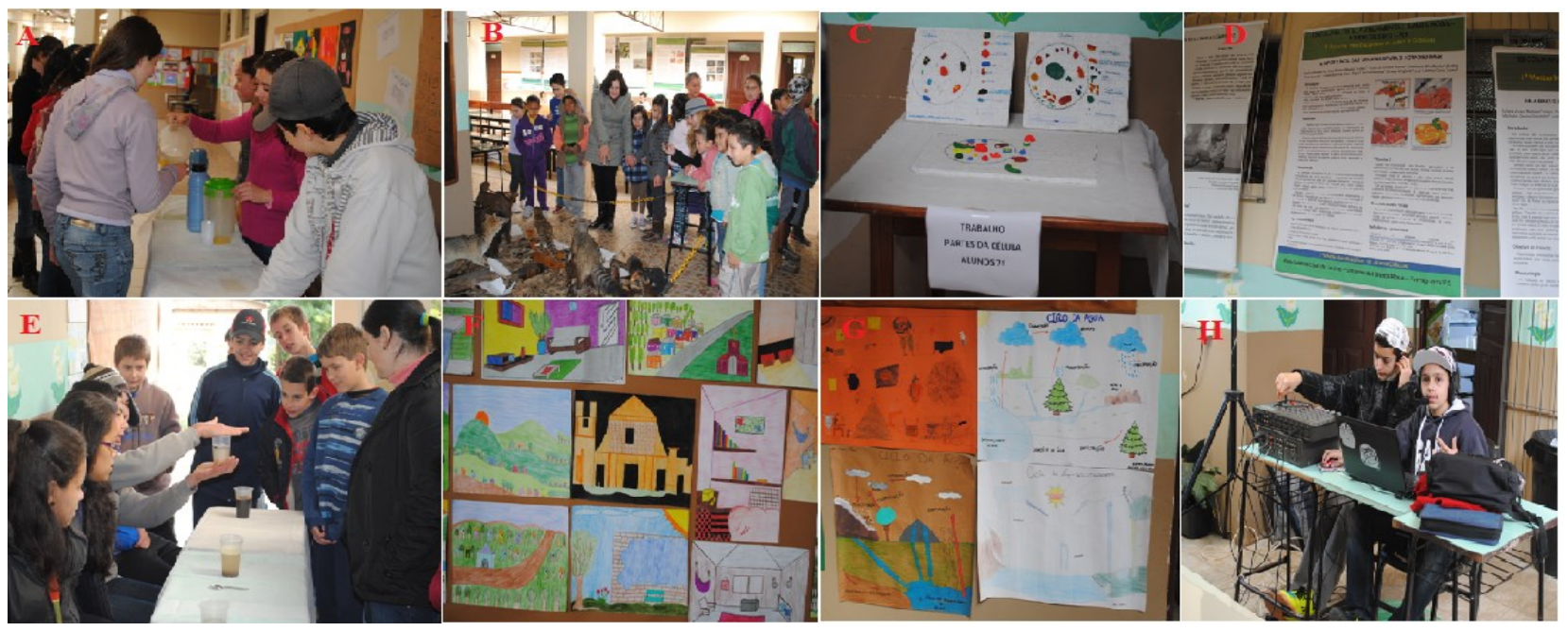

Figura 1: (A) Degustação de sucos e chás naturais; (B) Alunos e comunidade observando espécimes taxidermizados e participando na mostra; (C) Modelo de célula animal; (D) Baners; (E) demonstração de misturas básicas utilizando corantes em água; (F) Desenhos figurativos; (G) Cartaz apresentando o ciclo da água; (H) Alunos voluntários participando na sonorização do evento. Fotos: Luiz Corrêa. 
Torna-se importante realizar no município de Formigueiro uma mostra interdisciplinar de trabalhos, onde todas as escolas locais possam participar e apresentar trabalhos em conjunto, proporcionando momentos de ensino, quanto trocas de experiências interagindo entre a comunidade local e escolar.

\section{AGRADECIMENTOS}

Somos gratos as todos que de forma direta ou indireta participaram na organização e desenvolvimento do evento.

\section{REFERÊNCIAS}

LENZ, A. M. S.; HERBER, J. Feira de Ciências: um projeto de iniciação a pesquisa. Destaques Acadêmicos, v.5, n.2, p.69-75, 2013.

MAINARDI, A.; MULHER, L.; PEREIRA, A. A. O cenário educacional: O professor e a Tecnologia da Informação e Comunicação diante das mudanças atuais. Revista Eletrônica em Gestão, Educação e Tecnologia Ambiental, v. 18, n. 1, p.531-544, 2014.

MEZZARI, S. ; FROTA, P. R. de O. ; MARTINS, M, da C. Feiras multidisciplinares e o ensino de Ciências. Revista Electrónica de Investigación y Docencia, n.1, p. 107-119, 2011.

NEUENFELDT, A. E. ; RODRIGUES, W. da L. Interdisciplinaridade na escola: uma possibilidade a partir do texto como eixo organizador de unidades didáticas

interdisciplinares. Revista Iberoamericana de Educación,v.5, n. 54, p.1 - 10, 2011.

SANTOS, A; R. dos. Metodologia científica: a construção do conhecimento. $5^{\circ}$ ed.: Rio de Janeiro - DP \& A, 2002. 168p.

STÜLP, S.; MARTINS, S. N. SANTINI, R. de; GIONGO, I. M. Feira de ciências univates: descobrindo talentos para a pesquisa. Destaques acadêmicos, v.4, n. 4, p. 17-22, 2013 